PATIENT CARE

\title{
A Modified Advanced Cardiac Life Support Algorithm
}

\section{Abdulhalim Jamal Kinsara*}

Associate professor of Cardiology, Ministry of National Guard Health Affair. King Abdullah international research center, King Saud bin Abdulaziz University for Health Sciences, COM-WR

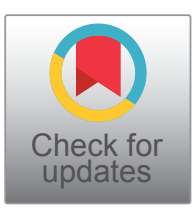

*Corresponding author: Abdulhalim Jamal Kinsara, FRCP, FACC, Associate Professor of cardiology, Ministry of National Guard Health Affair. King Abdullah international research center. King Saud bin Abdulaziz University for Health Sciences, COM-WR, PO Box 9515, Jeddah 21423, Saudi Arabia, Tel: 966-12-2266666

\begin{abstract}
Advanced cardiac life support (ACLS) has been made with many algorithms. We are suggesting a simple combined one as a time frame expected to attend is minutes and maintaining coherent neurological status is crucial.
\end{abstract}

\section{Keywords}

Advanced cardiac life support, Algorithms, Tachyarrhythmia, Bradyarrhythmia, Shock

\section{Key Messages}

- A time frame approach is expected in cardiac arrest and minutes count to maintain a coherent neurological status.

- A joined Tachy/Brady algorithm is feasible.

- A simple combined algorithm for cardiac life support is presented.

Advanced cardiac life support (ACLS) has been made simpler, shorter and with many algorithms. Despite that, many candidates still have a fear of taking the course.
In institutions with multiple nationalities, the way in which ACLS is taught might vary and the time frame expected to attend the important minutes in saving a life and maintaining coherent neurological status might been delayed.

We have come up with the attached algorithm (Figure 1) to unify the approach, make it faster and more effective. We hope it will result in us saving more lives. We have divided the algorithm into two halves: Living and dead.

Life will usually emphasize treatment of tachy/ brady, and the concept of assessing stability, with expert consultation in the case of a stable patient, while dead will emphasize treatment as shockable or non-shockable to prompt early shock and the consideration of differential diagnoses [1,2].

We focused on utilizing the alphabetic $A B C D E$ or once EMS. We also utilize a 5-step approach to recognize the rhythms. 


\section{ACLS SUMMARY!}

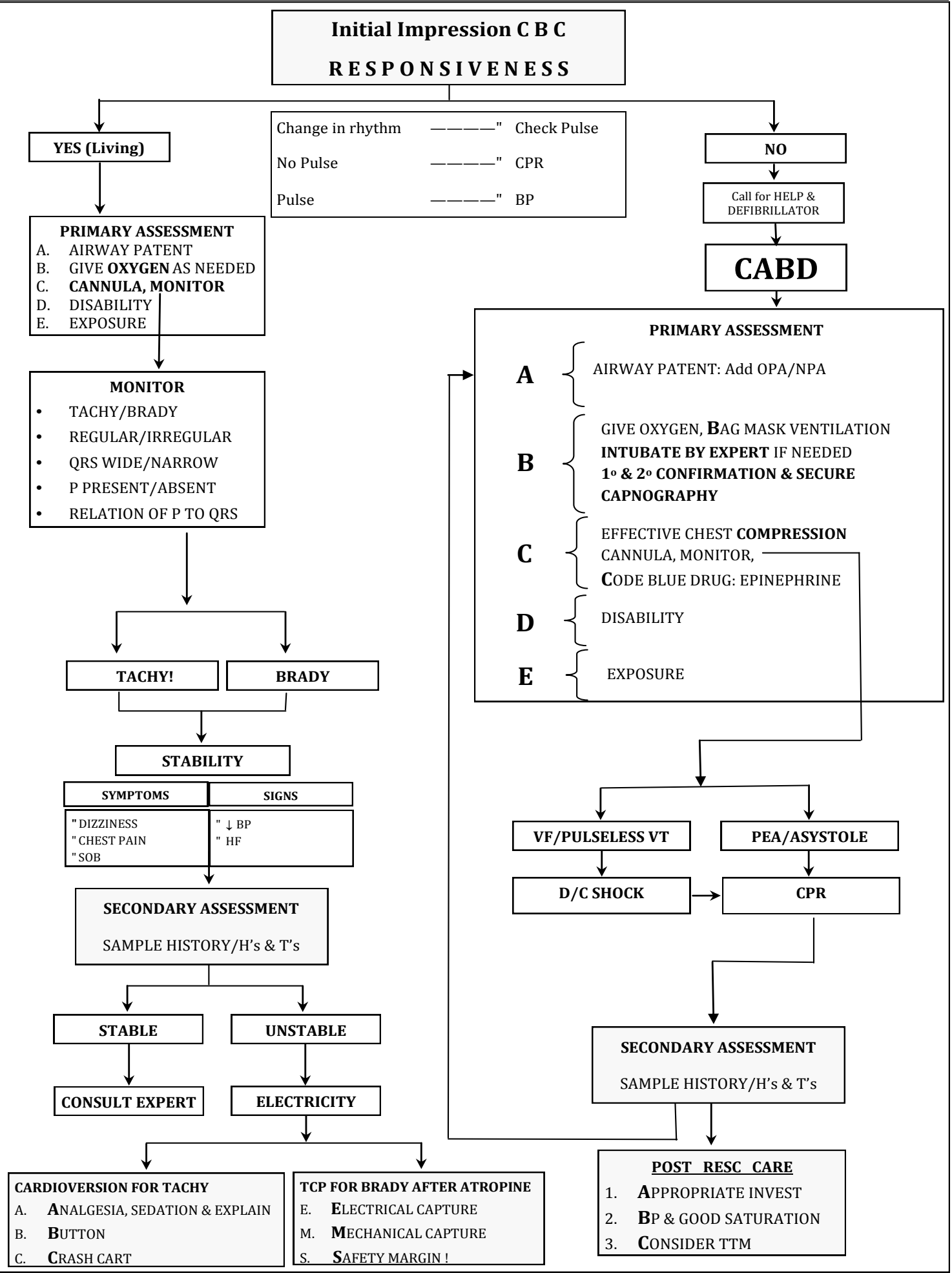

Figure 1: ACLS Summary.

\section{References}

1. Duff JP, Topjian A, Berg MD, Melissa Chan, Sarah E Haskell, et al. (2018) 2018 American Heart Association focused update on pediatric advanced life support: an update to the American Heart Association guidelines for cardiopulmonary resuscitation and emergency cardiovascular care. Circulation 138: e731-e739.
2. Soar J, Donnino MW, Aickin R, lan Maconochie, Dianne L Atkins, et al. (2018) 2018 international consensus on cardiopulmonary resuscitation and emergency cardiovascular care science with treatment recommendations summary. Circulation 138: e714-e730.

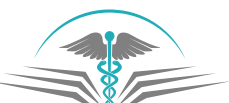

